\title{
The effects of obstructive sleep apnea and high- sensitivity C-reactive protein on clinical outcome in off-pump coronary artery bypass grafting
}

\section{Mingxin Gao}

Capital Medical University

\section{Kangjun Fan}

Capital Medical University

Wenyuan Yu

Capital Medical University

Hongli Liu

Capital Medical University

Yongxiang Wei

Capital Medical University

Yang Yu ( $\nabla$ heartyuyang@hotmail.com )

Capital Medical University Affiliated Anzhen Hospital https://orcid.org/0000-0002-8482-4626

\section{Research article}

Keywords: hs-CRP, OPCABG, POAF, duration of hospitalization, hospital costs, CHD

Posted Date: February 25th, 2021

DOl: https://doi.org/10.21203/rs.3.rs-258875/v1

License: (a) (i) This work is licensed under a Creative Commons Attribution 4.0 International License. Read Full License

Version of Record: A version of this preprint was published at BMC Cardiovascular Disorders on July 31st, 2021. See the published version at https://doi.org/10.1186/s12872-021-02168-2. 


\section{Abstract \\ Purpose}

This study aimed to investigate the relationship between obstructive sleep apnea (OSA) and high-sensitivity C-reactive protein (hs-CRP) to determine their effects on postoperative complications and clinical outcomes during hospitalization in patients undergoing off-pump cardiac artery bypass grafting (OPCABG).

\section{Methods}

This prospective, single-center study enrolled patients who underwent OPCABG. OSA was evaluated using a portable sleep monitor before OPCABG. Spearman correlation was performed to investigate the relationship between hs-CRP and polygraphy test indicators; regression analysis was performed to determine whether hs-CRP is an independent influencing factor for postoperative atrial fibrillation, duration of hospitalization, and hospital cost.

\section{Results}

Partial pressure of carbon dioxide $(P=0.033)$, high-sensitivity C-reactive protein (hs-CRP) $(P=0.001)$, apnea hypopnea index $(A H I)(P=0.000)$, mean apnea time $(P=0.000)$, maximum apnea time $(P=0.000)$, and ODI $\geq 3 \%(P=0.000)$ were significantly higher in the moderate-severe OSA group than in the absent-mild OSA group. $\operatorname{LVEF}(P=0.034)$, lowest arterial oxygen saturation $\left(\mathrm{SaO}_{2}\right)(P=0.000)$, and mean $\mathrm{SaO}_{2}(P=0.000)$ were significantly lower in the moderate-severe OSA group. Hs-CRP levels correlated with AHI ( $r s=0.235, P$ $=0.009), \mathrm{ODI} \geq 3 \%(r s=0.228, P=0.011)$, lowest $\mathrm{SaO}_{2}(r s=0.186, P=0.040)$, and mean $\mathrm{SaO}_{2}(r s=0.331, P$ $=0.000)$. AHI independently correlated with hs-CRP levels $(P=0.01)$; hs-CRP was an independent risk factor for post-CABG atrial fibrillation (POAF) $(\mathrm{OR}=1.17, \mathrm{P}=0.006)$; and hs-CRP level independently correlated with duration of hospitalization $(P=0.002)$ and hospital cost $(P=0.040)$.

\section{Conclusion}

Hs-CRP levels are closely related to the degree of OSA and have potential utility in predicting POAF, duration of hospitalization, and hospital costs in patients undergoing OPCABG.

\section{Introduction}

Obstructive sleep apnea (OSA) is characterized by repeated or partial obstruction of the respiratory tract during sleep, with an incidence of $9-38 \%$ in adults [1]. Intermittent hypoxia induced by OSA could trigger oxidative stress and could damage the vascular endothelium; for these reasons, it is an independent risk factor for coronary heart disease (CHD) and affects its prognosis [2]. Currently, off-pump cardiac artery bypass grafting (OPCABG) is one of the primary treatments of $\mathrm{CHD}$ [3]. However, there are few reports on 
whether OSA is associated with post-OPCABG complications [4]. Traditional OSA severity markers, such as apnea hypopnea index (AHI) have limitations in predicting the prognosis of CABG. Inflammatory processes are central to the pathogenesis of vascular diseases in the context of OSA. High-sensitivity C-reactive protein (hs-CRP) is a marker of acute inflammation and has strong sensitivity; a slight increase in hs-CRP level could indicate coronary plaque inflammation or coronary artery wall injury, which is closely related to $\mathrm{CHD}$ and its associated negative events [5].

In this study, we aimed to investigate the relationship between OSA and hs-CRP levels and to determine their effects on postoperative complications and clinical outcomes during postoperative hospitalization in patients who underwent OPCABG.

\section{Methods}

Study design

This prospective, single-center study enrolled patients who underwent OPCABG from January 2019 to December 2019 at Beijing An Zhen Hospital. This study was conducted in accordance with the Declaration of Helsinki and was approved by the institutional review board of Beijing An Zhen Hospital of Capital Medical University (approval no.: 2013025). All study participants gave informed written consent prior to participation.

\section{Patients}

The inclusion criteria were as follows: age, 40-75 years; with consent to undergo sleep monitoring tests (polygraphy; PG) using a portable sleep monitor; and provision of written informed consent for study participation. We excluded patients with valvular disease combined with other heart diseases, central sleep apnea, severe respiratory diseases (e.g., chronic obstructive pulmonary disease), severe diseases of other organs (e.g., renal failure), body temperature $>37.5^{\circ} \mathrm{C}$, and preoperative use of morphine and its analogs, sedative drugs, and/or theophylline. We recorded baseline clinical data, including age, sex, body mass index (BMI), body temperature, pre-existing medical conditions (hypertension, diabetes, stroke), history of smoking, blood biochemistry findings, and left ventricular ejection fraction (LVEF) bases on echocardiography, and PG test data.

PG tests and diagnostic criteria for OSA

Eligible patients were enrolled and admitted to the hospital. PG was performed before OPCABG. Each patient in the sleep monitoring center at Beijing An Zhen Hospital wore a portable sleep monitor (ApneaLink, ResMed, Australia). We used type III PG to detect airflow by nasal catheter, respiratory movement by chest belt, heart rate by electrocardiograph, and arterial oxygen saturation $\left(\mathrm{SaO}_{2}\right)$ by pulse oximetry. All PG test data were analyzed by two physicians at the Sleep Center of Beijing An Zhen Hospital. In case of disagreement between the two, a third physician participated in the data analysis. Sleep apnea was defined as the cessation of airflow through the nose and mouth for $>10 \mathrm{~s}$ during sleep; hypopnea, a reduction of $>$ $50 \%$ in the airflow intensity and $\geq 4 \%$ in $\mathrm{SaO}_{2}$ level during sleep. AHI was defined as the total number of 
apnea or hypopnea episodes per hour during sleep (i.e., $\mathrm{AHI}=$ total number of apnea or hypopnea episodes/total sleep duration $(\mathrm{min}) \times 60$ ). Moderate-severe OSA was defined as an AHI $\geq 15 / h$ during a 7-h sleep. Oxygen desaturation index $(\mathrm{ODI}) \geq 3 \%$ is the number of times that oxygen saturation decreases by $>$ $3 \%$ per hour [6]. All moderate-severe patients were recommended for continuous positive airway pressure (CPAP) after discharge.

\section{OPCABG}

All patients underwent OPCABG after the PG test. The same cardiac surgeon performed all surgeries. The number of grafts and surgical duration were recorded. The quality of graft anastomosis met the criteria recommended by the Operation Quality Committee of Beijing An Zhen Hospital. Two ultrasound specialists performed echocardiography in all patients, and a single nurse measured the blood pressure and collected blood samples from the patients. After surgery, the patients were monitored in the intensive care unit (ICU) until ventilator removal was feasible and vital signs were stable; they were discharged from the hospital once they could move freely. The physician in the ICU and the cardiac surgeon determined the ICU stay and hospitalization duration. We recorded the following postoperative data: incidence of major adverse cardiac and cerebrovascular event (MACCE), lung infection, post-CABG atrial fibrillation (POAF); duration of postoperative tracheal intubation; ICU stay; duration of hospitalization, and hospital cost. POAF was defined as the occurrence of AF within $72 \mathrm{~h}$ after surgery. Pulmonary infection was defined as a postoperative increase in white blood cell count, obvious inflammation based on postoperative chest radiography and computed tomography, and meeting one of the following conditions: sputum examination reveals new characteristic changes and pathogenic bacterium could be cultivated from blood or respiratory secretions.

Blinding

The cardiac surgeon, other participating investigators, and research staff were blinded to the findings of the PG tests. After the final enrolled patient was discharged from the hospital in January 2020 , all data were revealed to the participating investigators.

\section{Statistical analysis}

All statistical analyses were performed using SPSS, version 24.0 (SPSS Inc., Chicago, IL, USA). Continuous variables with a normal distribution were presented as means \pm standard deviations and were compared using independent samples $t$-tests. Continuous variables without a normal distribution were presented as medians (interquartile ranges) and were compared using rank-sum tests. Categorical variables are presented as percentages and were compared using $\chi 2$ tests. If the missing quantity of measurement data was $<5 \%$, the average value was used to replace the missing value. No missing values in the counting data were noted. Spearman correlation analysis was employed to determine the relationship between PG test data and hs-CRP; multiple linear regression was used to analyze the relationship between AHI and hs-CRP. Univariate binary logistic regression was used to analyze the relationship between preoperative relevant indicators and POAF occurrence. Indicators with $\mathrm{P}<0.1$ on univariate analysis were included in the multivariate binary logistic regression model to determine whether hs-CRP was an independent risk factor 
for POAF. Using a simple linear regression, we analyzed the relationship between relevant preoperative indicators and the duration of hospitalization and hospital cost. Indicators with $\mathrm{P}<0.1$ on univariate analysis were included in the multiple linear regression model to determine whether hs-CRP was an independent influencing factor for the duration of hospitalization and hospital cost. Two-sided P-values < 0.05 were considered statistically significant.

\section{Results}

OSA prevalence and hs-CRP

The study flow chart is shown in Fig. 1. One hundred seventy-five patients underwent PG and OPCABG from January 2019 to December 2019. A total of 123 patients were included in the final analysis. Based on the PG findings, 71 patients had an $A H I<15$ and were assigned to the absent-mild OSA group, while the remaining 52 had an $\mathrm{AHI} \geq 15$ and were assigned to the moderate-severe OSA group. We set the threshold hs-CRP level at $2 \mathrm{mg} / \mathrm{L}$, which is according to the results of previous large clinical trials. Seventy-eight patients had an hs-CRP level of $<2 \mathrm{mg} / \mathrm{L}$ and were assigned to the normal hs-CRP group; 45 had an hs-CRP level of $\geq 2 \mathrm{mg} / \mathrm{L}$ and were assigned to the elevated hs-CRP group.

Preoperative clinical data of the absent-mild OSA and moderate-severe OSA groups were compared (Table 1): $\mathrm{PCO}_{2}(\mathrm{P}=0.033)$, hs-CRP ( $\mathrm{P}=0.001$; Fig. 2$), \mathrm{AHI}$, mean apnea time, maximum apnea time, and $\mathrm{ODI} \geq 3 \%$ (all $P=0.000$ ) were significantly higher in the moderate-severe OSA group than in the absentmild OSA group. LVEF $(P=0.034)$ and lowest and mean $\mathrm{SaO}_{2}$ (both $\left.P=0.000\right)$ were significantly lower in the moderate-severe OSA group than in the absent-mild OSA group. No significant difference in other preoperative indexes was found. In addition, the number of grafting performed, duration of surgery, MACCEs, lung infection, POAF, duration of ventilator use, ICU stay, duration of hospitalization, and hospital cost were not significantly different between the two OSA groups (Table 2). 
Table 1

Baseline clinical data for patients with obstructive sleep apnea (OSA) undergoing off-pump coronary artery bypass grafting (OPCABG)

\begin{tabular}{|c|c|c|c|c|}
\hline & $\begin{array}{l}\text { Absent-mild OSA } \\
(n=71)\end{array}$ & $\begin{array}{l}\text { Moderate-severe OSA } \\
(n=52)\end{array}$ & $P$ value & $\begin{array}{l}\text { Total } \\
(n=123)\end{array}$ \\
\hline Sex (male/female) & $55 / 16$ & $39 / 13$ & 0.750 & $94 / 29$ \\
\hline Age (years) & $61.3 \pm 9.3$ & $62.9 \pm 8.2$ & 0.334 & $62.0 \pm 8.88$ \\
\hline BMI $\left(\mathrm{kg} / \mathrm{m}^{2}\right)$ & $25.5 \pm 3.2$ & $25.2 \pm 3.7$ & 0.602 & $25.4 \pm 3.4$ \\
\hline Body temperature $\left({ }^{\circ} \mathrm{C}\right)$ & $36.4 \pm 0.4$ & $36.3 \pm 0.4$ & 0.236 & $36.3 \pm 0.4$ \\
\hline Hypertension, n (\%) & $49(69)$ & $40(77)$ & 0.333 & $89(72)$ \\
\hline Diabetes, n (\%) & $27(38)$ & $24(46)$ & 0.366 & $51(42)$ \\
\hline Stroke, n (\%) & $9(13)$ & $2(4)$ & 0.090 & $11(9)$ \\
\hline Smoking history $\mathrm{n}(\%)$ & $33(47)$ & $28(54)$ & 0.419 & $61(50)$ \\
\hline \multicolumn{5}{|l|}{ Blood test data } \\
\hline $\mathrm{PO}_{2}(\mathrm{mmHg})$ & $94.2 \pm 18.2$ & $88.9 \pm 25.5$ & 0.183 & $92.0 \pm 21.7$ \\
\hline $\mathrm{PCO}_{2}(\mathrm{mmHg})$ & $35.5 \pm 3.2$ & $37.1 \pm 4.4$ & $0.033^{*}$ & $36.2 \pm 3.8$ \\
\hline $\mathrm{HDL}(\mathrm{mmol} / \mathrm{L})$ & $1.1 \pm 0.3$ & $1.0 \pm 0.3$ & 0.273 & $1.0 \pm 0.3$ \\
\hline LDL (mmol/L) & $2.4 \pm 1.0$ & $2.5 \pm 1.1$ & 0.677 & $2.4 \pm 1.0$ \\
\hline Triglyceride (mmol/L) & $1.3(1.1,1.9)$ & $1.3(1.0,1.8)$ & 0.916 & $1.3(1.1,1.8)$ \\
\hline Creatinine $(\mu \mathrm{mol} / \mathrm{l})$ & $73.3 \pm 17.8$ & $76.8 \pm 21.4$ & 0.319 & $74.8 \pm 19.4$ \\
\hline hs-CRP (mg/L) & $1.1(0.3,2.2)$ & $2.0(0.7,6.8)$ & $0.001 *$ & $1.4(0.5,3.5)$ \\
\hline \multicolumn{5}{|l|}{ Echocardiography data } \\
\hline LVEF (\%) & $59.5 \pm 8.5$ & $55.9 \pm 9.8$ & $0.034^{*}$ & $58.0 \pm 9.2$ \\
\hline LVDD (mm) & $48.9 \pm 6.7$ & $50.0 \pm 5.9$ & 0.326 & $49.4 \pm 6.4$ \\
\hline LAD (mm) & $36.7 \pm 3.8$ & $37.0 \pm 4.2$ & 0.645 & $36.9 \pm 4.0$ \\
\hline \multicolumn{5}{|l|}{ PG test data } \\
\hline \multicolumn{5}{|c|}{ Values are mean $( \pm S D)$, median (interquartile range), or no. (\%). } \\
\hline \multicolumn{5}{|c|}{$\begin{array}{l}\mathrm{BMI} \text { : body mass index, } \mathrm{PO}_{2} \text { : partial pressure of oxygen, } \mathrm{PCO}_{2} \text { : partial pressure of carbon dioxide, } \mathrm{HDL} \text { : } \\
\text { high-density lipoprotein, } \mathrm{LDL} \text { : low-density lipoprotein, hs-CRP: high-sensitivity C-reactive protein, } \mathrm{LVEF} \text { : } \\
\text { left ventricular ejection fraction, } \mathrm{LVDD} \text { : left ventricular end diastolic diameter, LAD: left atrium diameter, } \\
\text { AHI: apnea hypopnea index, } \mathrm{SaO}_{2} \text { : arterial oxygen saturation, ODI: oxygen desaturation index. }\end{array}$} \\
\hline \multicolumn{5}{|l|}{$* P<0.05$} \\
\hline
\end{tabular}




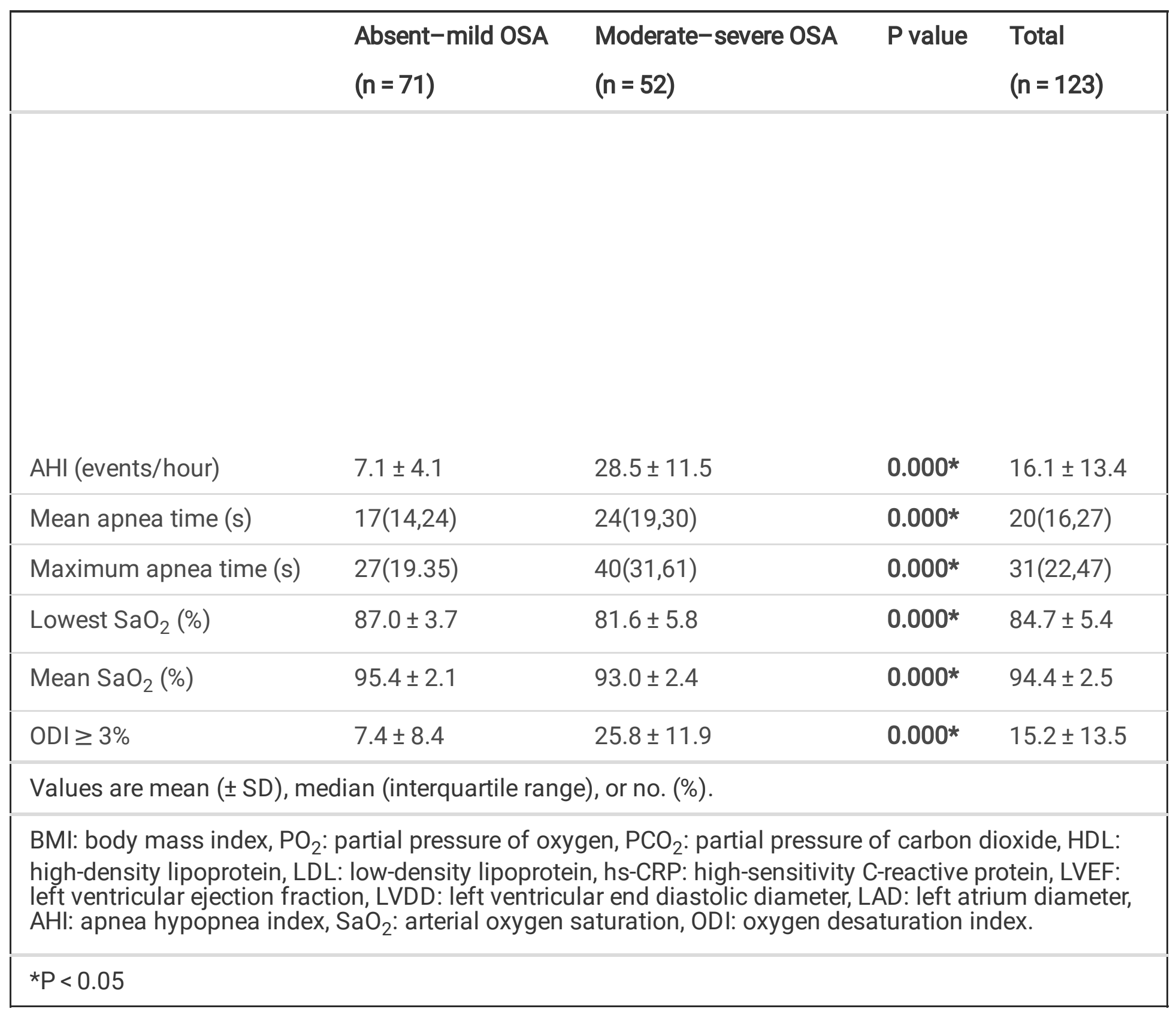


Table 2

Comparison of intraoperative and postoperative clinical data between patients with absent-mild obstructive sleep apnea (OSA) and those with moderate-severe OSA who underwent off-pump coronary artery bypass grafting (OPCABG)

\begin{tabular}{|lllll|}
\hline & $\begin{array}{l}\text { Absent-mild } \\
\text { OSA } \\
(\mathbf{n = 7 1 )}\end{array}$ & $\begin{array}{l}\text { Moderate-severe OSA } \\
(\mathbf{n}=\mathbf{5 2})\end{array}$ & P value & $\begin{array}{l}\text { Total } \\
(\mathbf{n}=123)\end{array}$ \\
\hline No. of performed grafting & $4.2 \pm 0.6$ & $4.2 \pm 0.5$ & 0.849 & $4.2 \pm 0.5$ \\
\hline Duration of surgery (min) & $233.6 \pm 35.7$ & $229.4 \pm 34.7$ & 0.525 & $231.8 \pm 35.2$ \\
\hline MACCEs, $\mathrm{n}(\%)$ & $21(30)$ & $11(21)$ & 0.293 & $32(26)$ \\
\hline Lung infection, $\mathrm{n}(\%)$ & $2(3)$ & $2(4)$ & 0.751 & $4(3)$ \\
\hline POAF, $n(\%)$ & $16(23)$ & $16(31)$ & 0.304 & $32(26)$ \\
\hline Duration of ventilator use (hour) & $21.1 \pm 19.6$ & $20.3 \pm 13.3$ & 0.799 & $20.8 \pm 17.2$ \\
\hline ICU stay (hour) & $34.0 \pm 31.3$ & $30.4 \pm 22.8$ & 0.478 & $32.5 \pm 28.0$ \\
\hline Duration of hospitalization (day) & $17.2 \pm 5.7$ & $18.8 \pm 6.7$ & 0.176 & $17.9 \pm 6.2$ \\
\hline Hospital cost $(\times 1000$ RMB) & $128.4 \pm 25.6$ & $134.0 \pm 28.7$ & 0.260 & $130.8 \pm 27.0$ \\
\hline Values are mean $( \pm$ SD), median (interquartile range), or no. (\%). & & \\
\hline MACCEs: major adverse cardiac or cerebrovascular events, POAF: postoperative atrial fibrillation. \\
\hline
\end{tabular}

A comparison of postoperative clinical data between the normal hs-CRP and elevated hs-CRP groups (Fig. 3) showed that the proportion of patients with moderate-severe OSA and that of patients with POAF were significantly higher in the elevated hs-CRP group than in the normal hs-CRP group ( $56 \%$ vs. $35 \%, P=$ $0.024 ; 38 \%$ vs. $19 \%, P=0.024)$. The duration of hospitalization $(P=0.000)$ and hospital cost $(P=0.000)$ in

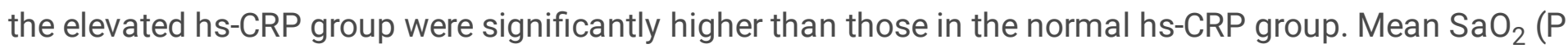
$=0.012)$ in the elevated hs-CRP group was significantly lower than that in the normal hs-CRP group.

Relationship between hs-CRP level and PG test indexes

Spearman correlation analysis showed positive correlations between hs-CRP levels and $\mathrm{AHI}(\mathrm{rs}=0.235, \mathrm{P}=$ $0.009)$ and $\mathrm{ODI} \geq 3 \%(\mathrm{rs}=0.228, \mathrm{P}=0.011)$. hs-CRP levels negative correlated with the lowest $\mathrm{SaO}_{2}(\mathrm{rs}=$ $0.186, \mathrm{P}=0.040)$ and mean $\mathrm{SaO}_{2}(\mathrm{rs}=0.331, \mathrm{P}=0.000)$. Multiple linear regression showed that $\mathrm{AHI}$ and hsCRP levels were significantly correlated $(P=0.01)$ after correcting for sex, age, and BMI.

Correlation of hs-CRP level with POAF, duration of hospitalization, and hospital cost.

POAF, duration of hospitalization, and hospital costs were significantly different between the normal hsCRP and elevated hs-CRP groups. To determine whether hs-CRP level was an independent influencing factor for these three indicators, logistic regression analyses (for POAF) and linear regression analysis (for 
duration of hospitalization and hospital cost) were performed. Table 3 shows that hs-CRP level was an independent risk factor for POAF (OR $=1.17, P=0.006)$. Table 4 shows that hs-CRP level $(P=0.002)$ and LVEF $(P=0.002)$ independently correlated with the duration of hospitalization; hypertension $(P=0.014)$, hsCRP level $(P=0.040)$, and $\operatorname{LVEF}(P=0.000)$ independently correlated with hospital costs.

Table 3

Univariate logistic regression and multivariate logistic regression analyses for the correlation between various preoperative clinical indicators and postoperative atrial fibrillation

\begin{tabular}{|c|c|c|c|c|}
\hline & Univariate & & Multivariate & \\
\hline \multirow[t]{2}{*}{ Covariate } & Odds ratio & $P$ value & Odds ratio & $P$ value \\
\hline & \multicolumn{2}{|l|}{$(95 \% \mathrm{Cl})$} & \multicolumn{2}{|l|}{$(95 \% \mathrm{Cl})$} \\
\hline Sex & $0.720(0.288-1.800)$ & 0.482 & & \\
\hline Age & $1.028(0.980-1.078)$ & 0.260 & & \\
\hline BMI & $1.043(0.925-1.176)$ & 0.491 & & \\
\hline Hypertension & $1.507(0.582-3.900)$ & 0.398 & & \\
\hline Diabetes & $0.668(0.289-1.545)$ & 0.346 & & \\
\hline Stroke & $1.073(0.267-4.320)$ & 0.921 & & \\
\hline Smoking history & $0.430(0.186-0.993)$ & $0.048 *$ & $0.360(0.142-0.912)$ & $0.031 *$ \\
\hline $\mathrm{PCO}_{2}$ & $0.924(0.829-1.030)$ & 0.156 & & \\
\hline Hs-crp & $1.166(1.050-1.294)$ & $0.004^{*}$ & $1.170(1.045-1.310)$ & $0.007^{*}$ \\
\hline LVEF & $0.949(0.909-0.991)$ & $0.017 *$ & $0.961(0.914-1.011)$ & 0.122 \\
\hline LAD & $1.095(0.988-1.214)$ & 0.083 & $1.084(0.964-1.220)$ & 0.151 \\
\hline $\mathrm{AHI}$ & $1.014(0.985-1.044)$ & 0.342 & & \\
\hline \multicolumn{5}{|c|}{$\begin{array}{l}\mathrm{BMI} \text { : body mass index, } \mathrm{PCO}_{2} \text { : partial pressure of carbon dioxide, hs-CRP: high-sensitivity C-reactive } \\
\text { protein, } \mathrm{LVEF} \text { : left ventricular ejection fraction, } \mathrm{LAD} \text { : left atrium diameter, AHI: apnea hypopnea index. }\end{array}$} \\
\hline \multicolumn{5}{|l|}{$* P<0.05$} \\
\hline
\end{tabular}


Table 4

Single logistic regression analysis and multivariate logistic regression analysis for the correlation between various preoperative clinical indicators and postoperative atrial fibrillation, duration of hospitalization, and hospital cost

\begin{tabular}{|c|c|c|c|c|c|c|c|c|}
\hline \multirow[b]{3}{*}{ Covariate } & \multicolumn{4}{|c|}{$\begin{array}{l}\text { Dependent variable: duration of } \\
\text { hospitalization }\end{array}$} & \multicolumn{4}{|c|}{ Dependent variable: hospital cost } \\
\hline & \multicolumn{2}{|c|}{ Univariate } & \multicolumn{2}{|c|}{ Multivariate } & \multicolumn{2}{|l|}{ Univariate } & \multicolumn{2}{|c|}{ Multivariate } \\
\hline & $\begin{array}{l}\text { B } \\
(95 \% \mathrm{Cl})\end{array}$ & $\begin{array}{l}\mathrm{P} \\
\text { value }\end{array}$ & $\begin{array}{l}\text { B } \\
(95 \% \mathrm{Cl})\end{array}$ & $\begin{array}{l}\mathrm{P} \\
\text { value }\end{array}$ & $\begin{array}{l}\text { B } \\
(95 \% \mathrm{Cl})\end{array}$ & $\begin{array}{l}P \\
\text { value }\end{array}$ & $\begin{array}{l}\text { B } \\
(95 \% \mathrm{Cl})\end{array}$ & $\begin{array}{l}P \\
\text { value }\end{array}$ \\
\hline Sex & $\begin{array}{l}0.868 \\
(-1.730- \\
3.465)\end{array}$ & 0.510 & & & $\begin{array}{l}-0.327 \\
(-11.717- \\
11.063)\end{array}$ & 0.955 & & \\
\hline Age & $\begin{array}{l}-0.026 \\
(-0.151- \\
0.099)\end{array}$ & 0.678 & & & $\begin{array}{l}0.270 \\
(-0.274- \\
0.815)\end{array}$ & 0.328 & & \\
\hline BMI & $\begin{array}{l}-0.025 \\
(-0.348- \\
0.299)\end{array}$ & 0.880 & & & $\begin{array}{l}-0.954 \\
(-2.360- \\
0.452)\end{array}$ & 0.182 & & \\
\hline Hypertension & $\begin{array}{l}-2.131 \\
(-4.570- \\
0.309)\end{array}$ & 0.086 & $\begin{array}{l}-2.085 \\
(-4.317- \\
0.147)\end{array}$ & 0.067 & $\begin{array}{l}-13.934 \\
(-24.450- \\
3.418)\end{array}$ & $0.010 *$ & $\begin{array}{l}-12.191 \\
(-21.633- \\
2.749)\end{array}$ & $0.012^{*}$ \\
\hline Diabetes & $\begin{array}{l}0.457 \\
(-1.784- \\
2.697)\end{array}$ & 0.687 & & & $\begin{array}{l}1.819 \\
(-7.990- \\
11.627)\end{array}$ & 0.714 & & \\
\hline Stroke & $\begin{array}{l}0.442 \\
(-3.427- \\
4.312)\end{array}$ & 0.821 & & & $\begin{array}{l}-9.151 \\
(-26.013- \\
7.712)\end{array}$ & 0.285 & & \\
\hline $\begin{array}{l}\text { Smoking } \\
\text { history }\end{array}$ & $\begin{array}{l}1.331 \\
(-0.865- \\
3.527)\end{array}$ & 0.232 & & & $\begin{array}{l}4.810 \\
(-4.821- \\
14.441)\end{array}$ & 0.325 & & \\
\hline $\mathrm{PCO}_{2}$ & $\begin{array}{l}0.063 \\
(-0.227- \\
0.354)\end{array}$ & 0.666 & & & $\begin{array}{l}-0.360 \\
(-1.633- \\
0.913)\end{array}$ & 0.577 & & \\
\hline
\end{tabular}

BMI: body mass index, $\mathrm{PCO}_{2}$ : partial pressure of carbon dioxide, hs-CRP: high-sensitivity C-reactive protein, LVEF: left ventricular ejection fraction, AHI: apnea hypopnea index.

${ }^{*} \mathrm{P}<0.05$ 


\begin{tabular}{|c|c|c|c|c|c|c|c|c|}
\hline \multirow[b]{2}{*}{ Creatinine } & \multicolumn{4}{|c|}{$\begin{array}{l}\text { Dependent variable: duration of } \\
\text { hospitalization }\end{array}$} & \multicolumn{4}{|c|}{ Dependent variable: hospital cost } \\
\hline & 0.003 & 0.905 & & & 0.051 & 0.688 & & \\
\hline & $\begin{array}{l}(-0.054- \\
0.061)\end{array}$ & & & & $\begin{array}{l}(-0.199- \\
0.301)\end{array}$ & & & \\
\hline \multirow[t]{2}{*}{ Hs-crp } & 0.501 & $0.000 *$ & 0.398 & $0.002^{*}$ & 1.080 & $0.005^{*}$ & 1.081 & $0.041 *$ \\
\hline & $\begin{array}{l}(0.251- \\
0.751)\end{array}$ & & $\begin{array}{l}(0.154- \\
0.642)\end{array}$ & & $\begin{array}{l}(0.500- \\
2.750)\end{array}$ & & $\begin{array}{l}(0.047- \\
2.113)\end{array}$ & \\
\hline \multirow[t]{2}{*}{ LVEF } & -0.235 & $0.000 *$ & -0.168 & $0.003^{*}$ & -1.346 & $0.000 *$ & -1.099 & $0.000 *$ \\
\hline & $\begin{array}{l}(-0.347- \\
0.122)\end{array}$ & & $\begin{array}{l}(-0.280- \\
0.056)\end{array}$ & & $\begin{array}{l}(-1.814- \\
0.877)\end{array}$ & & $\begin{array}{l}(-1.571- \\
0.627)\end{array}$ & \\
\hline \multirow[t]{2}{*}{$\mathrm{AHI}$} & 0.112 & $0.007 *$ & 0.067 & 0.090 & 0.441 & $0.015^{*}$ & 0.251 & 0.131 \\
\hline & $\begin{array}{l}(0.031- \\
0.192)\end{array}$ & & $\begin{array}{l}(-0.011- \\
0.144)\end{array}$ & & $\begin{array}{l}(0.087- \\
0.795)\end{array}$ & & $\begin{array}{l}(-0.076- \\
0.578)\end{array}$ & \\
\hline \multicolumn{9}{|c|}{$\begin{array}{l}\mathrm{BMI} \text { : body mass index, } \mathrm{PCO}_{2} \text { : partial pressure of carbon dioxide, hs-CRP: high-sensitivity C-reactive } \\
\text { protein, LVEF: left ventricular ejection fraction, } \mathrm{AHI} \text { : apnea hypopnea index. }\end{array}$} \\
\hline$\star P<0.05$ & & & & & & & & \\
\hline
\end{tabular}

\section{Discussion}

OSA is closely related to CHD. A study showed that the prevalence of CHD in patients with OSA was $16.2 \%$ and that of patients without OSA was 5.4\% [7]; in a population with suspected CHD, the proportion of patients with moderate-severe OSA was $24 \%$, four times higher than the prevalence in the normal population [8]. In the present study, we found that the proportion of patients with moderate-severe OSA was $42.3 \%$, significantly higher than that of the aforementioned study. This finding could be because the patients with OSA in our study needed to undergo OPCABG. Moreover, the patients had severe coronary atherosclerotic lesions, which indicates that OSA is a substantial risk factor for CHD.

In addition, we found that the preoperative LVEF of patients with moderate-severe OSA was significantly lower than that of patients with absent-mild OSA. Previous studies also found that LVEF was independently related to moderate-severe OSA. The main mechanisms by which OSA affects cardiac function may be as follows $[9,10]$ : first, each respiratory obstruction event could result in an intrathoracic negative pressure of $60-70 \mathrm{~cm} \mathrm{H}_{2} \mathrm{O}$, and hypoxia could cause pulmonary vasoconstriction, resulting in 
preload and afterload imbalance between the left and right ventricles; subsequently, myocardial oxygen consumption increases and myocardial ischemia occurs, which in turn alters cardiac function; second, the long-term repeated fluctuation of intrathoracic pressure could increase intraglomerular pressure variability, leading to impaired cardiac function; and finally, sympathetic hyperactivity affects all-day cardiopulmonary hemodynamics. In addition, hypopharyngeal edema due to decreased cardiac function could also promote the development of OSA.

CABG is one of the primary treatments of CHD. Few studies showed that OSA may affect the prognosis of patients with CABG; Uchôa et al. found that moderate-severe OSA significantly increased the long-term incidence of MACCEs (follow-up time of 4.5 years), revascularization rate, the proportion of angina attacks, and $A F$ incidence in patients with CABG; there was no significant effect on the 30-day prognosis after CABG [11]. Another study found that AHI was an independent risk factor for increased duration of hospitalization and postoperative circulatory fluctuation in patients with CABG [12]. In contrast, we found no significant difference in postoperative indicators, including the duration of hospitalization, between the moderatesevere OSA and absent-mild OSA groups. The possible reason for the discrepancy is that all patients included in our study underwent OPCABG, which in turn avoided the effects of extracorporeal circulation, shortening the postoperative recovery cycle, and reducing the short-term effect of OSA.

Evidence to identify the effect of OSA on the prognosis of OPCABG only using OSA classification is insufficient. OSA may affect the clinical outcome of CABG by influencing other indicators. For example, our previous study found that OSA may further affect the perioperative indicators such as the cardiac function [4]. In addition, biomarkers related to OSA and CHD may also be examined to predict more accurately the effect of OSA on CABG.

CRP is an acute phase reaction protein. Repeated hypoxia and inadequate ventilation in OSA could trigger oxidative stress and systemic inflammatory response, which could in turn enhance the synthesis and release of CRP [13]. Shamsuzzaman et al. showed that CRP has a significant linear correlation with AHI and is an independent influencing factor for OSA severity [14]. Moreover, inflammatory responses play key roles in the development of atherosclerosis. CRP, which is the product and mediator of inflammatory responses in atherosclerosis, is an important marker of endothelial dysfunction. Elevated CRP levels have been shown to be an independent risk factor for diseases such as myocardial infarction, peripheral vascular disease, and stroke [15]. Han et al. found that high CRP levels influence acute renal function injury, all-cause death, duration of hospitalization, and ICU stay after CABG [16].

Compared with the CRP, hs-CRP extends the detection linear range from 3-200 mg/L to $0.005-0.10 \mathrm{mg} / \mathrm{L}$, thereby making the determination of low-concentration CRP more accurate. hs-CRP has a long half-life, with no diurnal difference and no sex- or age-dependence and has a higher value in predicting the prognosis of cardiovascular and cerebrovascular diseases [17]. Previous studies have shown a relationship between hsCRP levels and OSA, nevertheless, these results are controversial because of obesity and various confounding factors in previous studies [18]. In our study, we found that the hs-CRP level was significantly increased in the moderate-severe OSA group, and there were significant correlations between hs-CRP level 
and several indicators of $\mathrm{PG}\left(\mathrm{AHI}, \mathrm{ODI} \geq 3 \%\right.$, lowest $\mathrm{SaO}_{2}$, mean $\left.\mathrm{SaO}_{2}\right)$. Multiple linear regression showed that $\mathrm{AHI}$ was an factor affecting hs-CRP level, independent of obesity.

Hs-CRP plays an important role in predicting the prognosis of cardiovascular disease; nevertheless, only one report on the early effect of hs-CRP on OPCABG has been conducted [19]. In the present study, we found that elevated hs-CRP levels were significantly associated with increased AF incidence and duration of hospitalization. Our results also demonstrated that AF incidence, duration of hospitalization, and hospital costs were significantly higher in the elevated hs-CRP group than in the normal group after OPCABG. Further regression analysis showed that hs-CRP level was an independent risk factor for POAF and was independently correlated with the duration of hospitalization and hospital cost.

As previously mentioned, OSA could affect hs-CRP levels, and preoperative hs-CRP level predicts postoperative indicators of OPCABG. CPAP, which could reduce the CRP level, is an important treatment for OSA [20]. For these reasons, the results of our study may suggest the utility of CPAP in patients with OSA who undergo CABG.

Stability of respiratory regulation is an important factor in determining OSA severity [21]. Compared with the normal population, patients with OSA had significantly reduced respiratory center responses to low $\mathrm{PaO}_{2}$ and high $\mathrm{PaO}_{2}$ during sleep, and the respiratory center response of some patients was also suppressed during wakefulness. Moreover, patients with OSA have long durations of apnea at night with short intervals. While hyperventilation occurs at the end of an apneic event, it is insufficient to clear the accumulated $\mathrm{CO}_{2}$, thereby resulting in hypercapnia or even type II respiratory failure. In this study, we found that the periods of apnea were significantly longer and the $\mathrm{PaCO}_{2}$ level was significantly higher in the moderate-severe OSA group than in the absent-mild OSA group when awake. Further study involving the change in $\mathrm{PaCO}_{2}$ and internal environment is needed.

Our study has the following limitations: first, it is a single-center study with a limited sample size; the results need to be validated using multi-center, large-sample studies. Second, we were unable to use polysomnography (PSG), which appears to offer a more accurate evaluation of OSA than does PG. Also, PG may underestimate the OSA severity. PSG requires patients to sleep at the sleep center for more than $8 \mathrm{~h}$. The sleep center in our hospital has not been provided with urgent response equipment and medical teams for patients with heart disease. All of our patients had severe coronary artery disease and were consequently at a high risk of emergent cardiac events. Therefore, we decided to use a portable PG monitor so that we could keep our patients in the cardiac surgery department for the assessment of OSA. Finally, we only analyzed hs-CRP levels at one time point; thus, it remains unclear as to whether hs-CRP level has the same predictive value at other time points.

\section{Conclusions}

Moderate-severe OSA has a higher incidence in patients who undergo OPCABG. Compared with patients with absent-mild OSA, those with moderate-severe OSA have poorer cardiac function and higher $\mathrm{PCO}_{2}$ and hs-CRP levels. The hs-CRP level is closely related to the severity of OSA and has an important predictive 
value for POAF, duration of hospitalization, and hospital cost among patients with OPCABG. The effect of OSA on the short-term prognosis of OPCABG may be predicted using preoperative hs-CRP levels.

\section{Declarations}

\section{Acknowledgments}

The authors of this study would like to thank all the study participants.

\section{Conflicts of interest}

All authors certify that they have no affiliations with or involvement in any organization or entity with any financial interest (such as honoraria; educational grants; participation in speakers' bureaus; membership, employment, consultancies, stock ownership, or other equity interest; and expert testimony or patentlicensing arrangements) or non-financial interest (such as personal or professional relationships, affiliations, knowledge, or beliefs) in the subject matter or materials discussed in this manuscript.

\section{Funding}

This study was supported by the International Science \& Technology Cooperation Program of China (No. 2015DFA30160), Beijing Municipal Science \& Technology Commission (No. Z141100006014057), and Beijing Municipal Administration of Hospitals Ascent Plan (No. DFL20150602). The funds were used to acquire portable sleep monitors for the study. The sponsor had no role in the design or conduct of this research.

\section{Ethical approval}

This study was approved by the Institutional Review Board of Beijing An Zhen Hospital of Capital Medical University (Approval No: 2013025).

\section{Consent to participate}

All study participants gave informed written consent prior to participation.

\section{Consent for publication}

All study participants gave informed written consent prior to participation.

\section{Availability of data and material}

All data generated or analysed during this study are included in this published article (and its supplementary information files).

\section{Code availability}

Not applicable 


\section{Authors' contributions}

Dr Gao and Fan contributed equally to this article.

\section{References}

[1] Senaratna CV, Jennifer LP, Lodge CJ et al (2017) Prevalence of obstructive sleep apnea in the general population: a systematic review. Sleep Med Rev 34:70-81

[2] Levy P, Ryan S, Oldenburg O, Parati G (2013) Sleep apnoea and the heart. Eur Respir Rev 22:333-352

[3] Neumann FJ, Sousa-Uva M, Ahlsson A et al (2019) ESC Scientific Document Group 2018 ESC/EACTS Guidelines on myocardial revascularization. Eur Heart J 40:87-165

[4] Gao M, Wang P, Tang T et al Effects of obstructive sleep. apnea hypopnea syndrome on postoperative complications in patients who undergo off-pump coronary artery bypass grafting. Sleep Breath In press

[5] Ridker PM (2016) A test in context: high-sensitivity c-reactive protein. J Am Coll Cardiol 67:712-723

[6] Kapur VK, Auckley DH, Chowdhuri S et al (2017) Clinical practice guideline for diagnostic testing for adult obstructive sleep apnea: an American Academy of Sleep Medicine Clinical Practice Guideline. J Clin Sleep Med 13:479-504

[7] Peker Y, Carlson J, Hedner J (2006) Increased incidence of coronary artery disease in sleep apnoea: a long-term follow-up. Eur Respir J 28:596-602

[8] Mooe T, Rabben T, Wiklund U, Franklin KA, Eriksson P (1996) Sleep-disordered breathing in men with coronary artery disease. Chest 109:659-663

[9] Kasai T, Floras JS, Bradley TD (1996) Sleep apnea and cardiovascular disease: a bidirectional relationship. Circulation 126:1495-1510

[10] Yumino D, Redolfi S, Ruttanaumpawan P et al (2010) Nocturnal rostral fluid shift: a unifying concept for the pathogenesis of obstructive and central sleep apnea in men with heart failure. Circulation 121:1598-1605

[11] Uchôa CH, Danzi-Soares NJ, Nunes FS et al (2015) Impact of OSA on cardiovascular events after coronary artery bypass surgery. Chest 147:1352-1360

[12] Tafelmeier M, Weizenegger T, Ripfel S et al (2018) Postoperative complications after elective coronary artery bypass grafting surgery in patients with sleep-disordered breathing. Clin Res Cardiol 107:1148-1159

[13] Guven SF, Turkkani MH, Ciftci B, Ciftci TU, Erdogan Y (2012) The relationship between high-sensitivity creactive protein levels and the severity of obstructive sleep apnea. Sleep Breath 16:217-221 
[14] Shamsuzzaman AS, Winnicki M, Lanfranchi P et al (2002) Elevated c-reactive protein in patients with obstructive sleep apnea. Circulation 105:2462-2464

[15] Szmitko PE, Wang CH, Weisel RD, de Almeida JR, Anderson TJ, Verma S (2003) New markers of inflammation and endothelial cell activation: part I. Circulation 108:1917-1923

[16] Han SS, Kim DK, Kim S, Chin HJ, Chae DW, Na KY (2017) C-reactive protein predicts acute kidney injury and death after coronary artery bypass grafting. Ann Thorac Surg 104:804-810

[17] Rifai N, Tracy RP, Ridker PM (1999) Clinical efficacy of an automated high-sensitivity C-reactive protein assay. Clin Chem 45:2136-2141

[18] Van der Touw T, Andronicos NM, Smart N (2019) Is c-reactive protein elevated in obstructive sleep apnea? A systematic review and meta-analysis. Biomarkers 24:429-435

[19] Mirhosseini SJ, Forouzannia SK, Ali-Hassan-Sayegh S, Ravan HV, Abdollahi MH, Mozayan MR (2012) Preoperative c-reactive protein can predict early clinical outcomes following elective off-pump CABG surgery in patients with severe left ventricle dysfunction. Saudi J Anaesth 6:327-331

[20] Gottlieb DJ, Punjabi NM, Mehra R et al (2014) CPAP versus oxygen in obstructive sleep apnea. N Engl J Med 370:2276-2285

[21] White DP (2017) Advanced concepts in the pathophysiology of obstructive sleep apnea. Adv Otorhinolaryngol 80:7-16

\section{Figures}




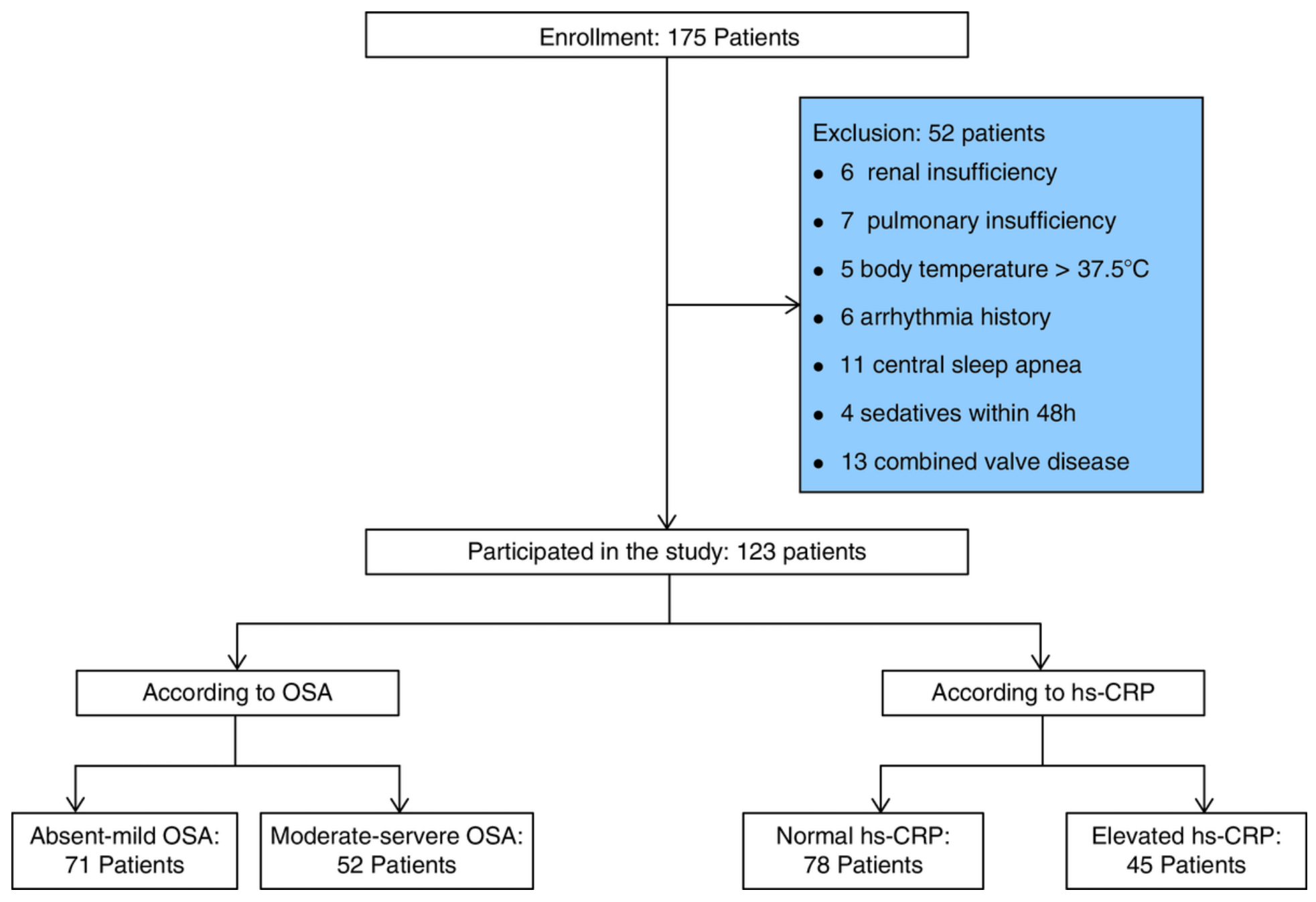

\section{Figure 1}

Flow chart showing the inclusion of patients in this study. 


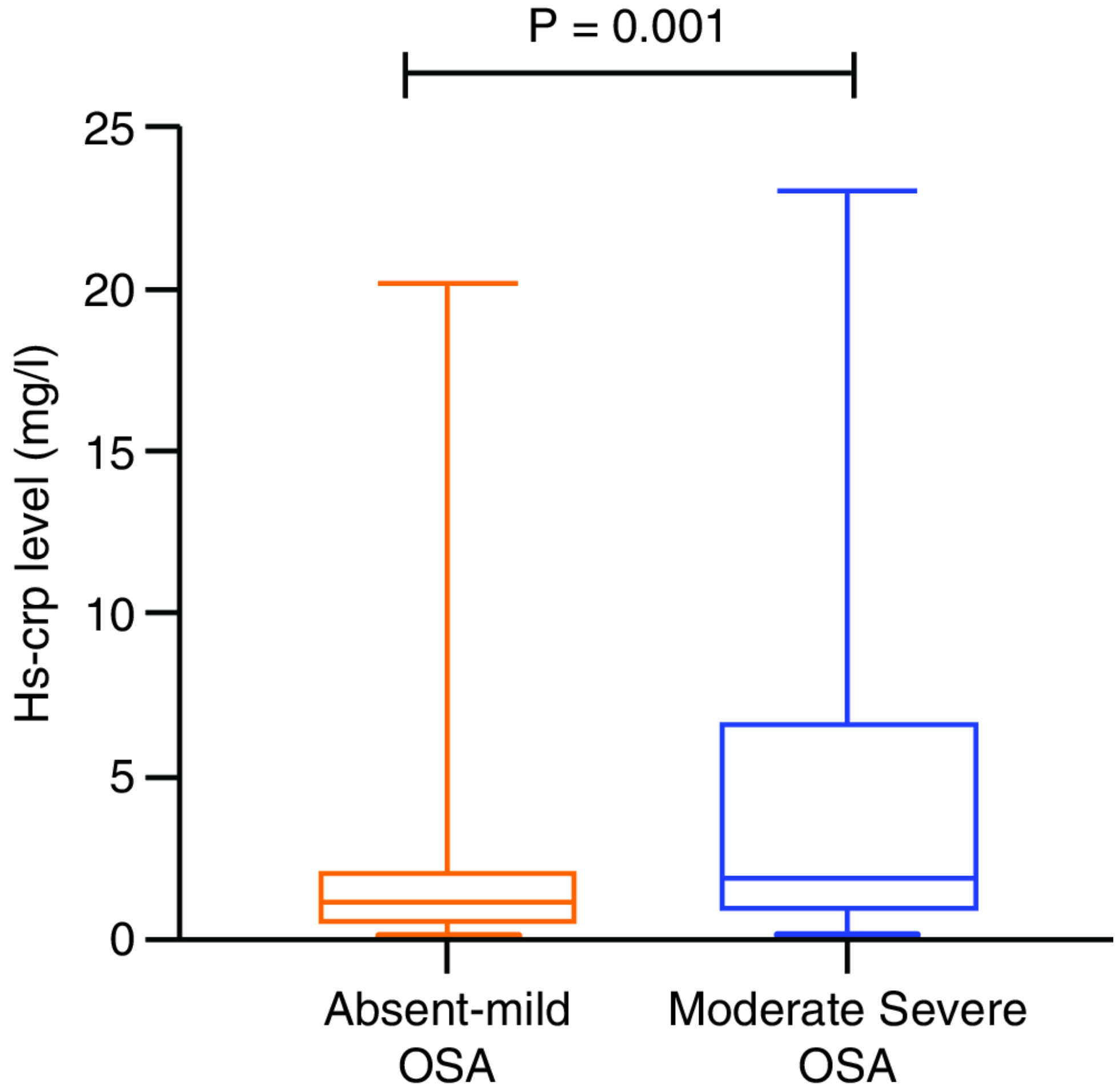

Figure 2

The hs-CRP level in the moderate-severe OSA group was significantly higher than that in the no-mild OSA group. 

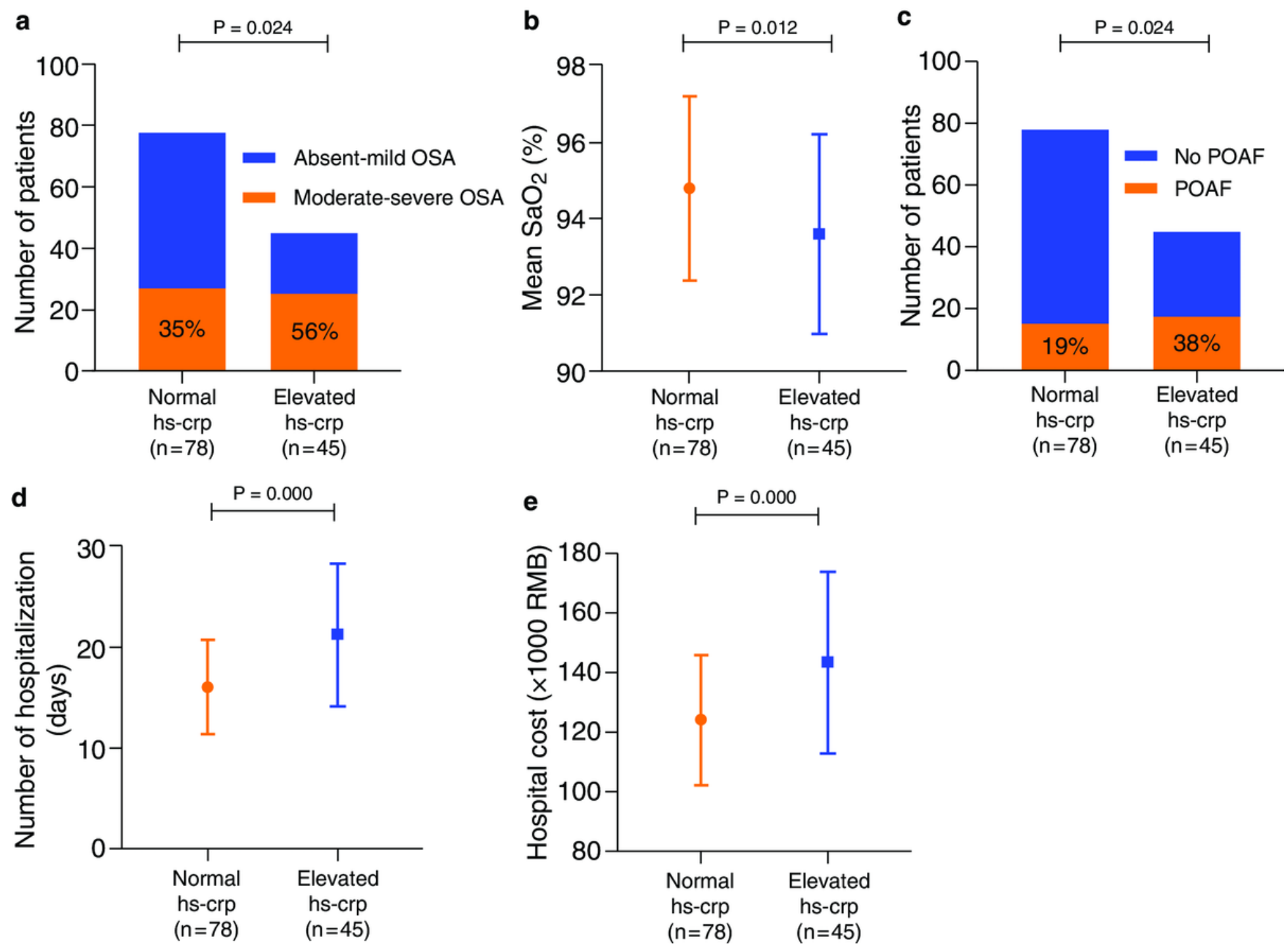

\section{Figure 3}

A The proportion of patients with moderate-severe OSA in the elevated hs-CRP group was significantly higher than that in the normal hs-CRP group. B The mean $\mathrm{SaO} 2$ in the elevated hs-CRP group was significantly lower than that in the normal hs-CRP group. C The proportion of patients with POAF in the elevated hs-CRP group was significantly higher than that in the normal hs-CRP group. D The duration of hospitalization in the elevated hs-CRP group was significantly longer than that in normal group. E The hospital cost in the elevated hs-CRP group was significantly greater than that in the normal hs-CRP group. 